OPEN ACCESS

Edited by:

Laura Galiana,

University of Valencia, Spain

Reviewed by:

Masanori Isobe,

Kyoto University, Japan

Ruth Zhuozhuo Shen,

South China Normal University, China

*Correspondence:

Dan Deng

100079@cqmu.edu.cn

Specialty section:

This article was submitted to

Health Psychology,

a section of the journal

Frontiers in Psychology

Received: 08 August 2021 Accepted: 22 November 2021 Published: 10 December 2021

Citation:

Peng $X$, Pu Y, Jiang $X$, Zheng $Q$, Gu J, Zhou H and Deng D (2021) Analysis of Factors That Influenced the Mental Health Status of Public Health Workers During the COVID-19

Epidemic Based on Bayesian

Networks: A Cross-Sectional Study.

Front. Psychol. 12:755347.

doi: 10.3389/fpsyg.2021.755347

\section{Analysis of Factors That Influenced the Mental Health Status of Public Health Workers During the COVID-19 Epidemic Based on Bayesian Networks: A Cross-Sectional Study}

\author{
Xin Peng ${ }^{1}$, Yangyang $\mathrm{Pu}^{2}$, Xiaoyong Jiang ${ }^{3}$, Qingmei Zheng ${ }^{4}$, Jing $\mathrm{Gu}^{5}$, Huan Zhou ${ }^{6}$ and \\ Dan Deng ${ }^{1 *}$ \\ 1 Department of Health Statistics, School of Public Health and Management, Chongqing Medical University, Chongqing, \\ China, ${ }^{2}$ Zigong First People's Hospital, Zigong, China, ${ }^{3}$ Health Education Institute, Zigong Center for Disease Control \\ and Prevention, Zigong, China, ${ }^{4}$ Chronic Disease Institute, Zigong Center for Disease Control and Prevention, Zigong, \\ China, ${ }^{5}$ School of Public Health, Sun Yat-sen University, Guangzhou, China, ${ }^{6}$ West China School of Public Health, Sichuan \\ University, Chengdu, China
}

Background: Public health workers are essential to responding to the coronavirus disease 2019 (COVID-19) epidemic, but research on anxiety and stress among public health workers during the epidemic is limited. This study aimed to evaluate related factors affecting mental health among public health workers during the epidemic.

Methods: Between February 19 and 25, 2020, an online, cross-sectional study was conducted among public health workers in a city in China. Mental health status was assessed using the Chinese versions of the Generalized Anxiety Disorder-7 (GAD-7) scale and Patient Health Questionnaire-9 (PHQ-9), both with a cutoff score of 5 . Work-related variables, workloads and sacrifices, and personal perceptions were also assessed.

Results: The prevalence of anxiety and depression were $49.2 \%$ and $45.7 \%$, respectively, among public health workers. Three risk factors and one protective factor, namely, overcommitment $(\mathrm{OR}=1.10 \sim 1.20, p<0.001)$, perceived troubles at work $(\mathrm{OR}=1.14 \sim 1.18, p<0.001)$, perceived tension $(\mathrm{OR}=1.11, p<0.001)$ and the capability to persist for more than 1 month at the current work intensity $(\mathrm{OR}=0.41 \sim 0.42, p<0.001)$ were found to be independently associated with anxiety and depression in the multivariable logistic regression analyses after propensity score matching. But the Bayesian networks analysis found that the last three factors directly affect anxiety and depression.

Conclusion: Psychological responses to COVID-19 were dramatic among public health workers during the severe phase of the outbreak. To minimize the impact of the epidemic, working conditions should be improved, and easily accessible psychological support services should be implemented.

Keywords: Bayesian network, COVID-19, anxiety, depression, public health workers 


\section{INTRODUCTION}

Mental health is an important component of health, and the concept of "no health without mental health" as proposed by the World Health Organization (WHO) has become the consensus view. Mental health problems are currently a prominent challenge worldwide. General estimates suggest that $11-18 \%$ of the world's population meets the criteria for a diagnosable psychiatric disorder at any given time (Wainberg et al., 2017). The drivers of poor mental health include multiple transitions affecting the global population, such as the increasing rates of some social determinants (pandemics, conflict, and displacement) and environmental threats (increased natural disasters associated with climate change) (Yokoyama et al., 2014; Patel et al., 2018). Alarmingly, in crisis situations, such as natural disasters or humanitarian emergencies, the prevalence rate of mental health disorders can reach nearly $22 \%$, which is nearly double the general prevalence (Charlson et al., 2019).

Many studies have suggested that infectious disease epidemics, including severe acute respiratory syndrome (SARS), Middle East respiratory syndrome (MERS), and 2009 novel influenza A (H1N1), are associated with mental health problems among the general population (Cowling et al., 2010; Taha et al., 2014), healthcare workers (HCWs) (Bai et al., 2004; Lee et al., 2018), and patients (Lee et al., 2007; Wang et al., 2011).

At the end of December 2019, an outbreak of coronavirus disease 2019 (COVID-19) occurred in Wuhan, Hubei Province, China (Wang et al., 2020). In only a month, the disease caused by severe acute respiratory syndrome coronavirus 2 (SARS-CoV-2) was declared a public health emergency by the WHO, and it was declared an epidemic in March 2020 (World Health Organization (WHO), 2020a). Due to the severe situation in the early stage of the epidemic, requiring a substantial amount of work in a short time, health systems were strained by the effort to contain the disease, which spread to over 200 countries throughout the world (World Health Organization (WHO), 2020b). In particular, healthcare workers, including public health workers, are the main persons involved in the screening and treatment of this disease, and they remain under great pressure.

The epidemic is still in a severe stage. As of 16 June 2021, there were about two hundred million confirmed cases of COVID-19, including 4,265,903 fatalities, reported to the WHO (World Health Organization (WHO), 2020c). Due to the limited effectiveness and insufficient supply of currently available vaccines, preventive measures, including controlling the sources of infection, impeding transmission, and protecting susceptible populations, are the most effective strategies to contain the spread of the disease (Li et al., 2020). Therefore, public health systems still face significant challenges in countries and regions where local epidemics remain severe. Public health systems vary among countries (Donaldson, 2008); China's public health system comprises specialized institutions [e.g., the Centers for Disease Control and Prevention (CDC)] as well as primary healthcare institutes (PHIs, e.g., community health centers in urban areas and village clinics in rural areas) (World Health Organization (WHO), 2015). Public health workers are usually affiliated with the $\mathrm{CDC}$ or PHIs and are mainly responsible for various prevention and control tasks, including the development of technical instructions, epidemiological investigation of patients and close contacts, surveillance of high-risk populations, collection and examination of specimens, and collection and reporting of data. A high level of overcommitment easily leads to physical and mental stress and exhaustion in healthcare workers (Siegrist, 2008), which, in turn, leads to anxiety and depression. Individuals who are overcommitted wish to be recognized and respected (Siegrist and $\mathrm{Li}, 2016$ ) and are especially sensitive to work pressure and negative emotions (Du Prel et al., 2018); thus, they face an increased chance of feeling misunderstood and wronged, among other troubles. During the epidemic, public health workers experienced rapid increases in work intensity and work pressure. During periods of intense work, they faced an increased risk of self-perceived work difficulties, which caused physical and mental stress and thus led to anxiety and depression. Overwork has taken a great toll on the physical and mental health of health care workers in particular. Therefore, studying the factors that influence the mental health of public health workers during the COVID-19 epidemic will provide reference data for other countries, protect the health of public health workers and help contain the epidemic.

Studies have shown that epidemics cause serious psychological distress among the general public and healthcare workers (Pappas et al., 2009). Several recent studies have shown that due to overwork, inadequate preparation, and emotional disturbances (such as fear of infection and concerns about family members) attributable to the COVID-19 epidemic, there is a high prevalence of mental health symptoms among medical professionals, including depression, insomnia, anxiety and posttraumatic stress disorder (PTSD) (Cai et al., 2020; Hou et al., 2020; Lai et al., 2020). However, most of the research on the factors influencing mental health has focused on doctors and nurses in hospital settings, rather than public health workers who are mainly affiliated with the CDC and PHIs.

Among the methodologies used to carry out such analyses, the classical methods predominated; such methods include descriptive statistics, multiple linear regressions, hierarchical linear regression, and multivariate logistic regression, among others. Most of these techniques do not allow descriptions of the complex, direct or conditional, and linear or nonlinear relationships between the variables considered in the model (García-Herrero et al., 2017). In reality, these factors may not be independent of each other and may have complex network relationships. Bayesian networks (BNs), also called belief networks, combine graph theory and probability theory to explore relationships between variables and are easily interpretable by means of the resulting graph (Larrañaga and Moral, 2011). The model has no strict requirements regarding data distribution; therefore, it can incorporate all the data to reveal the influences of various factors on mental health and the relationships between them. BNs have been widely used in many fields, including social and behavioral science (Aghaabbasi et al., 2020), clinical science (Beaudequin et al., 2020), occupational health (García-Herrero et al., 2017). However, no study to date has used a BN model to investigate the psychological impacts of the COVID-19 epidemic on populations. 
Therefore, the aims of the current study were to investigate the mental health status of public health workers during the outbreak and the influences on their mental health by using a $\mathrm{BN}$ model and to provide reference data for the development of targeted interventions for this population to improve their mental health during the COVID-19 epidemic. These goals are important for controlling the COVID-19 epidemic and improving public health workers' long-term health. Moreover, the findings from this investigation will be critical in addressing future outbreaks of emerging infectious diseases.

\section{MATERIALS AND METHODS}

\section{Study Design}

This cross-sectional study was conducted from February 19 to 25, 2020. Data were collected from a city in China. First, the city was divided into 5 districts and 2 counties according to the administrative plan, and 2 districts and 1 county were randomly selected. Each district/county selected 8 PHIs. The CDC staff of each district/county and the selected PHI staff participated in the survey, which was conducted entirely in China. The link to the questionnaire was distributed among participants (such as CDC workers) through WeChat/QQ working groups.

\section{Sample Size}

According to the purpose of the survey, the World Health Organization (WHO), 1991) recommended formula was used to estimate the total sample size required for this survey:

$$
n=\frac{Z^{2} P(1-P)}{d^{2}} \times d e f f
$$

$P$ was estimated based on a previously published study on mental health services during the COVID-19 outbreak in The Lancet Psychiatry; the prevalence of anxiety and depression among healthcare workers in Wuhan Province, China, were $44.7 \%$ and $50.7 \%$, respectively. Considering that this study was conducted in early February when the epidemic was most severe, the $P$-value was $40 \%$ (Liu et al., 2020). $Z$ was 1.96 considering a 0.05 type I error. deff (design effect) was 2.0. $d$ (the allowable absolute error level) was 5\%. Considering a response rate of $90 \%$, at least 800 public health workers were required to complete the online survey.

\section{Participant Recruitment and Online Survey Completion}

The participants met the following inclusion criteria: (1) aged 18 years or older; (2) worked at the CDC or PHI of that city during the study period; and (3) participated in COVID19 control and prevention-related work. All participants were informed of the background, aims, anonymous nature and length (approximately 10-15 $\mathrm{min}$ to complete the questionnaire) of the survey. Before the investigation, we conducted rigorous training for the investigators. We limited the training to 1 participant per unique internet protocol (IP) address. Only a completed questionnaire could be submitted. Questionnaires were quality-checked by a researcher to ensure accuracy. A total of 834 participants responded in this study. After strict quality control, 23 participants were excluded because of logical errors. Thus, 811 (97.24\%) participants effectively completed the survey. The studies involving human participants were reviewed and approved by the Chongqing Medical University. Completion of the questionnaire indicated informed consent of the participants.

\section{Measurements}

The questionnaire was obtained from the Cultivation Project of the "Three Major" Construction Scientific Research Projects of Sun Yat-sen University in 2020. Data on demographic characteristics [e.g., age, sex, job title, institution, and whether they had children under 6 years old (i.e., the school age)]; COVID-19 control and prevention work-related variables (e.g., type of work, time spent receiving COVID-19 training, knowledge of COVID-19 control and prevention strategies, difficulties in COVID-19 control and prevention); workloads and sacrifices (e.g., number of days with overtime work, number of hours of sleep per day on average, number of days with overnight work, number of working hours per day on average, practices to avoid infecting your family); perceptions related to COVID-19 and work, including whether one persist with more than 1 month or not at their current work intensity; the scores of 2 self-constructed scales (perceived distress at work and perceived tension at work); and the score of the Effort-Reward Imbalance (ERI) scale were collected (Niedhammer et al., 2004).

The primary psychological outcomes included symptoms of anxiety and depression, measured by the 7-item Generalized Anxiety Disorder (GAD-7) scale (Spitzer et al., 2006) and the 9item Patient Health Questionnaire (PHQ-9) (Wang et al., 2014), respectively. Probable mild anxiety and depression symptoms were defined by a minimum score of 5 points on the respective scales (Kroenke et al., 2001; Spitzer et al., 2006; Liu et al., 2020).

\section{Definition and Application of Bayesian Networks}

Bayesian networks (Koller and Friedman, 2009) consist of directed acyclic graphs (DAGs) and a set of conditional probability distributions (p). Nodes represent random variables, and directed edges represent the direct probability dependence between the corresponding variables $x_{i}$ and $\pi_{i}$. If there is an edge from $\pi_{i}$ to $x_{i}$ and the arrow points to $x_{i}$, then $\pi_{i}$ corresponds to the parents of $x_{i}$. In this case, the joint probability distribution can be factored in terms of conditioned probabilities:

$$
p\left(x_{1}, x_{2}, \ldots, x_{n}\right)=\prod_{i=1}^{n} p\left(x_{i} \mid \pi_{i}\right)
$$

Based on the data, both the graph and probabilities can be automatically constructed (Neapolitan, 2004) following structural learning and parameter learning. First, we need to define a score function to evaluate the degree of fit between the Bayesian network and the training data, and then find the Bayesian network with the best structure based on this score function. In this study, the Akaike information criterion 
TABLE 1 | Demographic characteristics of the anxiety groups before and after PSM ( $n, \%)$.

Demographics

\begin{tabular}{|c|c|c|c|c|c|c|}
\hline & \multicolumn{3}{|c|}{ Before PSM } & \multicolumn{3}{|c|}{ After PSM } \\
\hline & $\geq 5(n=399)$ & $<5(n=412)$ & Statistics $^{a}$ & $\geq 5(n=339)$ & $<5(n=339)$ & Statistics $^{a}$ \\
\hline \multicolumn{7}{|l|}{ Sex } \\
\hline Male & 134 (33.58\%) & $161(39.08 \%)$ & 2.643 & $122(35.99 \%)$ & 115 (33.92\%) & 0.318 \\
\hline Female & $265(66.42 \%)$ & $251(60.92 \%)$ & & $217(64.01 \%)$ & 224 (66.08\%) & \\
\hline Age & $37.96 \pm 9.52$ & $41.69 \pm 10.40$ & $5.329^{\star \star \star}$ & $39.37 \pm 9.40$ & $39.42 \pm 9.71$ & 0.602 \\
\hline \multicolumn{7}{|l|}{ Children under 6 years } \\
\hline No & 305 (76.44\%) & 347 (84.22\%) & $7.788^{\star \star}$ & 277 (81.71\%) & 276 (81.42\%) & 0.010 \\
\hline Yes & $94(23.56 \%)$ & 65 (15.78\%) & & 62 (18.29\%) & $63(18.58 \%)$ & \\
\hline \multicolumn{7}{|l|}{ Job title } \\
\hline Junior & $212(53.13 \%)$ & 220 (53.40\%) & 0.540 & 179 (52.80\%) & $180(53.10 \%)$ & 0.776 \\
\hline Intermediate/senior & 115 (28.82\%) & $111(26.94 \%)$ & & 95 (28.02\%) & 102 (30.09\%) & \\
\hline Other (e.g., volunteer) & 72 (18.05\%) & $81(19.66 \%)$ & & 65 (19.17\%) & $57(16.81 \%)$ & \\
\hline \multicolumn{7}{|l|}{ Institution } \\
\hline CDC & 142 (35.59\%) & $122(29.61 \%)$ & 3.298 & $123(36.28 \%)$ & 104 (30.68\%) & 2.391 \\
\hline $\mathrm{PHI}$ & 257 (64.41\%) & 290 (70.39\%) & & $216(63.72 \%)$ & 235 (69.32\%) & \\
\hline
\end{tabular}

TABLE 2 | Demographic characteristics of the depression groups before and after PSM $(n, \%)$.

\section{Demographics \\ Demographics}

\begin{tabular}{|c|c|c|c|c|c|c|}
\hline & \multicolumn{4}{|c|}{ Before PSM } & \multicolumn{2}{|c|}{ After PSM } \\
\hline & $\geq 5(n=371)$ & $<5(n=440)$ & Statistics $^{a}$ & $\geq 5(n=305)$ & $<5(n=305)$ & Statistics $^{a}$ \\
\hline \multicolumn{7}{|l|}{ Sex } \\
\hline Male & $114(30.72 \%)$ & $181(41.14 \%)$ & $9.422^{\star \star}$ & 109 (35.74\%) & 103 (33.77\%) & 0.260 \\
\hline Female & 257 (69.27\%) & 259 (58.86\%) & & 196 (64.26\%) & 202 (66.23\%) & \\
\hline Age & $37.72 \pm 9.70$ & $41.66 \pm 10.17$ & $5.612^{\star \star \star}$ & $39.41 \pm 9.66$ & $38.67 \pm 10.18$ & -0.918 \\
\hline \multicolumn{7}{|l|}{ Children under 6 years } \\
\hline No & 279 (75.20\%) & 373 (84.77\%) & $11.697^{\star \star}$ & 249 (81.64\%) & 244 (80.00\%) & 0.264 \\
\hline Yes & 92 (24.80\%) & 67 (15.23\%) & & $56(18.36 \%)$ & $61(20.00 \%)$ & \\
\hline \multicolumn{7}{|l|}{ Job title } \\
\hline Junior & 197 (53.10\%) & 235 (53.41\%) & $6.627^{\star}$ & $160(52.46 \%)$ & 166 (54.43\%) & 0.394 \\
\hline Intermediate/senior & $116(31.27 \%)$ & 110 (25.00\%) & & 93 (30.49\%) & $86(28.20 \%)$ & \\
\hline Other (e.g., volunteer) & $58(15.63 \%)$ & 95 (21.59\%) & & 52 (17.05\%) & $53(17.38 \%)$ & \\
\hline \multicolumn{7}{|l|}{ Institution } \\
\hline CDC & $151(40.70 \%)$ & 113 (25.68\%) & $20.679^{\star \star \star}$ & $114(37.38 \%)$ & $99(32.46 \%)$ & 1.623 \\
\hline $\mathrm{PHI}$ & 220 (59.30\%) & 327 (74.32\%) & & $191(62.62 \%)$ & 206 (67.54\%) & \\
\hline
\end{tabular}

PHQ-9, 9-item Patient Health Questionnaire; PSM, propensity score matching; CDC, Centers for Disease Control and Prevention; PHI, primary healthcare institute.

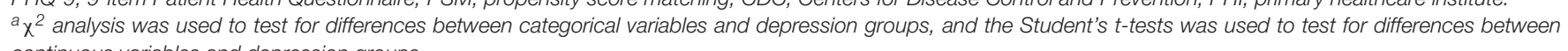
continuous variables and depression groups.

${ }^{*} p<0.05$.

${ }^{* *} p<0.01$.

${ }^{* * *} p<0.001$.

(AIC) algorithm is preferred. This algorithm was proposed by the Japanese statistician Akaike (1974). It is based on the concept of entropy as a standard to measure the quality of a statistical model. The smaller the AIC, the better the model is. The next step was to use maximum likelihood estimation (MLE) (Scutari and Denis, 2014) to learn the parameters to obtain the conditioned probabilities. The goal of MLE is to find a set of parameters $\theta$ to maximize the 
TABLE 3 | Univariate analysis results of variables related to anxiety after PSM (n, \%).

\begin{tabular}{|c|c|c|c|c|}
\hline \multirow[t]{2}{*}{ Variables } & \multicolumn{4}{|c|}{ Anxiety (GAD-7 score) } \\
\hline & $\geq 5(n=339)$ & $<5(n=339)$ & Statistics ${ }^{\#}$ & $P$ \\
\hline \multicolumn{5}{|c|}{ COVID-19 control and prevention work-related variables } \\
\hline \multicolumn{5}{|l|}{ Type of work } \\
\hline $\begin{array}{l}\text { Field work/non-field } \\
\text { work }\end{array}$ & $62(18.29 \%)$ & $87(25.66 \%)$ & 5.376 & 0.020 \\
\hline Both & $277(81.71 \%)$ & $252(74.34 \%)$ & & \\
\hline \multicolumn{5}{|c|}{ Time spent in COVID-19 training } \\
\hline$\leq 8 \mathrm{~h}$ & $70(20.65 \%)$ & $71(20.94 \%)$ & 3.029 & 0.220 \\
\hline $1-2$ days & $51(15.04 \%)$ & $36(10.62 \%)$ & & \\
\hline$>2$ days & $218(64.31 \%)$ & $232(68.44 \%)$ & & \\
\hline \multicolumn{5}{|c|}{ Sufficient knowledge of COVID-19 prevention and control measures } \\
\hline $\begin{array}{l}\text { Inadequate/very } \\
\text { inadequate }\end{array}$ & $5(1.47 \%)$ & $5(1.47 \%)$ & 0.509 & 0.775 \\
\hline Average & $88(25.96 \%)$ & $80(23.60 \%)$ & & \\
\hline $\begin{array}{l}\text { Adequate/relatively } \\
\text { adequate }\end{array}$ & $246(72.57 \%)$ & $254(74.93 \%)$ & & \\
\hline \multicolumn{5}{|c|}{ Number of difficulties in COVID-19 control and prevention } \\
\hline$\leq 5$ & $110(32.45 \%)^{\mathrm{a}}$ & $192(56.64 \%)$ & 46.761 & $<0.001$ \\
\hline $6-10$ & $176(51.92 \%)^{\mathrm{b}}$ & 129 (38.05\%) & & \\
\hline$>10$ & $53(15.63 \%)^{c}$ & $18(5.31 \%)$ & & \\
\hline \multicolumn{5}{|c|}{ Workloads and sacrifices } \\
\hline \multicolumn{5}{|c|}{ Number of days with overtime work } \\
\hline$\leq 5$ & $33(9.73 \%)$ & $42(12.39 \%)$ & 4.316 & 0.229 \\
\hline $6-10$ & $51(15.04 \%)$ & $63(18.58 \%)$ & & \\
\hline $11-15$ & $43(12.68 \%)$ & $48(14.16 \%)$ & & \\
\hline$>15$ & $212(62.54 \%)$ & $186(54.87 \%)$ & & \\
\hline \multicolumn{5}{|c|}{ Average sleep hours per day } \\
\hline$<5 \mathrm{~h}$ & $12(3.54 \%)^{a, b}$ & $11(3.24 \%)$ & 14.647 & 0.001 \\
\hline $5-6 \mathrm{~h}$ & $207(61.06 \%)^{\mathrm{b}}$ & 159 (46.90\%) & & \\
\hline$>6 \mathrm{~h}$ & $120(35.40 \%)^{\mathrm{a}}$ & 169 (49.85\%) & & \\
\hline \multicolumn{5}{|c|}{ Number of days with overnight work } \\
\hline 0 days & 189 (55.75\%) & $202(59.59 \%)$ & 1.259 & 0.533 \\
\hline $1-3$ days & $94(27.73 \%)$ & $82(24.19 \%)$ & & \\
\hline$>3$ days & $56(16.52 \%)$ & $55(16.22 \%)$ & & \\
\hline \multicolumn{5}{|c|}{ Average work time per day } \\
\hline$\leq 8 \mathrm{~h}$ & $76(22.42 \%)^{a}$ & $127(37.46 \%)$ & 19.732 & $<0.001$ \\
\hline $9-15 \mathrm{~h}$ & $242(71.39 \%)^{\mathrm{b}}$ & $201(59.29 \%)$ & & \\
\hline$>15 \mathrm{~h}$ & $21(6.19 \%)^{b}$ & $11(3.24 \%)$ & & \\
\hline \multicolumn{5}{|c|}{ Number of practices to avoid infecting your family } \\
\hline 0 & $40(11.80 \%)$ & 39 (11.50\%) & 2.145 & 0.342 \\
\hline $1-3$ & 244 (71.98\%) & $258(76.11 \%)$ & & \\
\hline $4-7$ & $55(16.22 \%)$ & 42 (12.39\%) & & \\
\hline \multicolumn{5}{|l|}{ Perceptions } \\
\hline \multicolumn{5}{|c|}{ How long one can persist with your current intensity of work } \\
\hline$<1$ month & 261 (76.99\%) & $184(54.28 \%)$ & 38.77 & $<0.001$ \\
\hline$\geq 1$ month & $78(23.01 \%)$ & $155(45.72 \%)$ & & \\
\hline $\begin{array}{l}\text { Perceived distress at } \\
\text { work }\end{array}$ & $13.42 \pm 3.26$ & $10.47 \pm 3.10$ & -12.06 & $<0.001$ \\
\hline Perceived tension & $29.18 \pm 5.46$ & $24.07 \pm 5.68$ & -11.94 & $<0.001$ \\
\hline $\begin{array}{l}\text { Overcommitment } \\
\text { the effort-reward } \\
\text { balance }\end{array}$ & $14.78 \pm 2.19$ & $13.12 \pm 2.39$ & -9.41 & $<0.001$ \\
\hline No & $145(42.77 \%)$ & $104(30.68 \%)$ & 48.497 & $<0.001$ \\
\hline Yes & $194(57.23 \%)$ & $235(69.32 \%)$ & & \\
\hline \multicolumn{5}{|c|}{$\begin{array}{l}\text { GAD-7, 7-item Generalized Anxiety Disorder; PSM, propensity score matching; } \\
\text { COVID-19, coronavirus disease } 2019 \text {. } \\
{ }^{\#} \chi^{2} \text { analysis was used to test for differences between categorical variables and } \\
\text { anxiety groups, and the Student's t-tests was used to test for differences between } \\
\text { continuous variables and anxiety groups. } \\
\text { Each superscript }(a, b, c) \text { letter denotes a subset of variables whose row } \\
\text { proportions do not differ significantly from each other at } p \leq 0.05 / 3=0.0167 \\
\text { level. Different subscript letter assignment between groups denotes a } \\
\text { significantly different pair of values based on post hoc testing with the } \\
\text { Bonferroni correction. } \\
\text { Variables with a p-value }<0.05 \text { are in bold. }\end{array}$} \\
\hline
\end{tabular}

probability of the model producing the observed data as follows:

$$
\hat{\theta}_{M L E}=\arg \max \sum_{i=1}^{n} \log P\left(x_{i} ; \theta\right)
$$

This set of parameters is the conditional probability of each node of the Bayesian network.

\section{Statistical Analysis}

Continuous variables are presented as means \pm standard deviations. Categorical variables are presented as percentages. Univariate analyses were performed using Student's $t$-tests for continuous variables and chi-square tests for categorical variables. We used chi-square tests with the Bonferroni correction for multiple comparison. So, the tripartite variables' the typical significance level of $p$-value $\leq 0.05$ was adjusted to $p$-value $\leq 0.05 / 3=0.0167$; and the $p$-value of the variable divided into four groups was adjusted to $p$-value $\leq 0.05 / 4=0.0125$. Due to the heterogeneity of the data, the demographic variables were not balanced. The measure implemented to control for demographic variables (age, sex, job title, institutions, and having children under 6 years old) was propensity score matching (PSM). The anxiety group and normal group and the depression group and normal group were 1:1 propensity-score matched, and the caliper value was set at 0.02 . The data obtained after matching were used in the univariate analyses. The matched data were used for subsequent statistical analyses.

Multivariate forward stepwise logistic regression models were constructed to identify the factors that influenced the anxiety and depression status of the respondents; all the COVID-19related variables that were found to be significant in the univariate analyses after PSM were entered into the multivariate analysis. Finally, independent factors were identified, and two outcomes (anxiety and depression) were included in the BN analysis. The statistical significance of all analyses was set at $p<0.05$. IBM SPSS Statistics 20, R 4.0.3 and GeNIe 2.4 Academic were used for data analysis.

\section{RESULTS}

\section{Univariate Analysis of Potential Factors Related to Anxiety and Depression Before and After Propensity Score Matching}

According to the score of GAD-7 and PHQ-9, all participants were divided into the score $\geq 5$ (anxiety or depression) and the score $<5$ (non-anxiety or non-depression) groups. Of the 811 participants, $399(49.2 \%)$ suffered from anxiety and 371 (45.7\%) suffered from depression, as shown in Tables 1, 2. More participants in the anxiety/depression group were younger and had children under 6 years than those in the non-anxiety/nondepression group. In addition, participants in the depression group were likely to be female, CDC worker and intermediate or senior job title than those in the non-depression group.

To further investigate the relationship between COVID-19related variables and mental health, PSM was used to control 
TABLE 4 | Univariate analysis results of variables related to depression after PSM (n, \%).

\begin{tabular}{|c|c|c|c|c|}
\hline \multirow[t]{2}{*}{ Variables } & \multicolumn{4}{|c|}{ Depression (PHQ-9 score) } \\
\hline & $\geq 5(n=305)$ & $<5(n=305)$ & Statistics ${ }^{\#}$ & $P$ \\
\hline \multicolumn{5}{|c|}{ COVID-19 control and prevention work-related variables } \\
\hline \multicolumn{5}{|l|}{ Type of work } \\
\hline Field work/non-field work & $63(20.66 \%)$ & $84(27.54 \%)$ & 3.952 & 0.047 \\
\hline Both & $242(79.34 \%)$ & $221(72.46 \%)$ & & \\
\hline \multicolumn{5}{|c|}{ Time spent in COVID-19 training } \\
\hline$\leq 8 \mathrm{~h}$ & $61(20.00 \%)$ & $66(21.64 \%)$ & 2.848 & 0.241 \\
\hline $1-2$ days & $47(15.41 \%)$ & $33(10.82 \%)$ & & \\
\hline$>2$ days & 197 (64.59\%) & $206(67.54 \%)$ & & \\
\hline \multicolumn{5}{|c|}{ Sufficient knowledge of COVID-19 prevention and control measures } \\
\hline $\begin{array}{l}\text { Inadequate/very } \\
\text { inadequate }\end{array}$ & $5(1.64 \%)$ & $3(0.98 \%)$ & 1.163 & 0.559 \\
\hline Average & $76(24.92 \%)$ & $68(22.30 \%)$ & & \\
\hline $\begin{array}{l}\text { Adequate/relatively } \\
\text { adequate }\end{array}$ & $224(73.44 \%)$ & $234(76.72 \%)$ & & \\
\hline \multicolumn{5}{|c|}{ Number of difficulties in COVID-19 control and prevention } \\
\hline$\leq 5$ & $105(34.43 \%)^{\mathrm{a}}$ & $173(56.72 \%)$ & 33.427 & $<0.001$ \\
\hline $6-10$ & $156(51.15 \%)^{b}$ & $113(37.05 \%)$ & & \\
\hline$>10$ & $44(14.43 \%)^{b}$ & $19(6.23 \%)$ & & \\
\hline \multicolumn{5}{|l|}{ Workloads and sacrifices } \\
\hline \multicolumn{5}{|c|}{ Number of days with overtime work } \\
\hline$\leq 5$ & $31(10.16 \%)^{a, b}$ & $43(14.10 \%)$ & 8.690 & 0.034 \\
\hline $6-10$ & $42(13.77 \%)^{\mathrm{a}}$ & $63(20.66 \%)$ & & \\
\hline $11-15$ & $42(13.77 \%)^{a, b}$ & $37(12.13 \%)$ & & \\
\hline$>15$ & $190(62.30 \%)^{b}$ & $162(53.11 \%)$ & & \\
\hline \multicolumn{5}{|l|}{ Average sleep hours per day } \\
\hline$<5 \mathrm{~h}$ & $11(3.61 \%)^{a, b}$ & $8(2.62 \%)$ & 10.701 & 0.005 \\
\hline $5-6 h$ & $181(59.34 \%)^{b}$ & $144(47.21 \%)$ & & \\
\hline$>6 \mathrm{~h}$ & $113(37.05 \%)^{\mathrm{a}}$ & $153(50.16 \%)$ & & \\
\hline \multicolumn{5}{|c|}{ Number of days with overnight work } \\
\hline 0 days & $172(56.39 \%)$ & $187(61.31 \%)$ & 1.610 & 0.447 \\
\hline $1-3$ days & $81(26.56 \%)$ & $74(24.26 \%)$ & & \\
\hline$>3$ days & $52(17.05 \%)$ & $44(14.43 \%)$ & & \\
\hline \multicolumn{5}{|l|}{ Average work time per day } \\
\hline$\leq 8 \mathrm{~h}$ & $82(26.89 \%)^{\mathrm{a}}$ & $115(37.70 \%)$ & 8.485 & 0.014 \\
\hline $9-15 h$ & $207(67.87 \%)^{b}$ & 179 (58.69\%) & & \\
\hline$>15 \mathrm{~h}$ & $16(5.25 \%)^{a, b}$ & $11(3.61 \%)$ & & \\
\hline \multicolumn{5}{|c|}{ Number of practices to avoid infecting your family } \\
\hline 0 & $32(10.49 \%)$ & 39 (12.79\%) & 1.499 & 0.473 \\
\hline $1-3$ & $235(77.05 \%)$ & $222(72.79 \%)$ & & \\
\hline $4-7$ & 38 (12.46\%) & $44(14.43 \%)$ & & \\
\hline \multicolumn{5}{|l|}{ Perceptions } \\
\hline \multicolumn{5}{|c|}{ How long one can persist with your current intensity of work } \\
\hline$<1$ month & $238(78.03 \%)$ & $174(57.05 \%)$ & 30.629 & $<0.001$ \\
\hline$\geq 1$ month & $67(21.97 \%)$ & $131(42.95 \%)$ & & \\
\hline Perceived distress at work & $13.27 \pm 3.29$ & $10.70 \pm 3.15$ & -9.883 & $<0.001$ \\
\hline Perceived tension & $28.95 \pm 5.67$ & $24.24 \pm 5.49$ & -10.427 & $<0.001$ \\
\hline Overcommitment & $14.61 \pm 2.25$ & $13.30 \pm 2.51$ & -6.773 & $<0.001$ \\
\hline \multicolumn{5}{|l|}{ The effort-reward balance } \\
\hline No & $130(42.62 \%)$ & $206(67.54 \%)$ & 38.271 & $<0.001$ \\
\hline Yes & $175(57.38 \%)$ & 99 (32.46\%) & & \\
\hline
\end{tabular}

PHQ-9, 9-item Patient Health Questionnaire; PSM, propensity score matching; COVID-19, coronavirus disease 2019.

${ }^{\#} \chi^{2}$ analysis was used to test for differences between categorical variables and depression groups, and the Student's t-tests was used to test for differences between continuous variables and depression groups.

Each superscript $(a, b)$ letter denotes a subset of variables whose row proportions do not differ significantly from each other (the tripartite variables' $p$-value was adjusted to $\leq 0.05 / 3=0.0167$; and the $p$-value of the variable divided into four groups was adjusted to $p$-value $\leq 0.05 / 4=0.0125$ ). Different subscript letter assignment between groups denotes a significantly different pair of values based on post hoc testing with the Bonferroni correction.

variables with a p-value $<0.05$ are in bold. for potential covariates. By searching the previous literature and consulting experts, we confirmed that certain demographic variables are risk factors for anxiety and depression (Kisely et al., 2020; Manh Than et al., 2020; Pappa et al., 2020; Xiao et al., 2020). Furthermore, young children are vulnerable to SARSCoV-2 infection and children under the age of 6 are more likely than older children to have severe and critical cases (Dong et al., 2020); therefore, parents of having children under 6 years old might feel especially burdened by the risk to their families. Rubin and Thomas (1996) suggested that all variables that might be associated with the outcome should be included in PSM. Therefore, we determined that sex, age, children under 6 years, job title, and institution should be included as covariables in the PSM analysis. There were 339 matches between the anxiety group and the normal group and 305 matches between the depression group and the normal group after PSM (Tables 1, 2).

The results of the univariate analyses of potential factors related to anxiety and depression symptoms after PSM are shown in Tables 3, 4. Participants in the anxiety group tended to do both field work and non-field work (81.71\% performing both types vs. $18.29 \%$ performing only one or the other, $p=0.020$ ), have 6-10 difficulties in COVID-19 control and prevention (51.92\%, compared to $32.45 \%$ with 5 or fewer difficulties; $p<0.001$, Bonferroni correction), sleep an average of 5-6 h per night (61.06\%, compared to $35.40 \%$ sleeping more than $6 \mathrm{~h}$ per night; $p<0.001$, Bonferroni correction), work $9-15 \mathrm{~h}$ per day $(71.39 \%$, compared to $22.42 \%$ working 8 or fewer hours per day; $p<0.001$, Bonferroni correction), be able to persist less than 1 month at their current work intensity $(76.99 \%$, compared to $23.01 \%$ persist 1 month or more, $p<0.001$ ), and perceived the effort-reward balance (57.23\%, compared to $42.77 \%$ perceiving an imbalance, $p<0.001)$.

Furthermore, participants in the depression group also tended to do both field work and non-field work (79.34\% performing both types vs. $20.66 \%$ performing only one or the other, $p=0.047)$, have 6-10 difficulties in COVID-19 control and prevention $(51.15 \%$, compared to $34.43 \%$ with 5 or fewer difficulties; $p<0.001$, Bonferroni correction), work overtime more than 15 days $(62.30 \%$, compared to $13.77 \%$ working overtime $6-10$ days; $p=0.012<0.0125$, Bonferroni correction), sleep an average of $5-6 \mathrm{~h}$ per night $(59.34 \%$, compared to $37.05 \%$ sleeping more than $6 \mathrm{~h}$ per night; $p=0.001$, Bonferroni correction) and work 9-15 h per day (67.87\%, compared to $26.89 \%$ working 8 or fewer hours per day; $p=0.006<0.0167$, Bonferroni correction) per day, be able to persist less than 1 month with current work intensity $(78.03 \%$, compared to $21.97 \%$ persist 1 month or more, $p<0.001$ ), and perceived the effort-reward balance $(57.38 \%$, compared to $42.62 \%$ perceiving an imbalance, $p<0.001)$. Moreover, participants with depression and anxiety had greater perceived distress, perceived tension, and overcommitment than those without depression or anxiety.

\section{Multivariate Stepwise Logistic Regression Analysis}

The associations between influencing factors and anxiety and depression symptoms among public health workers during 
TABLE 5 | Associations between mental health status and background variables (multivariate stepwise logistic regression) ${ }^{\mathrm{a}}$.

\begin{tabular}{|c|c|c|c|c|}
\hline \multirow[t]{2}{*}{ Variables } & \multicolumn{2}{|c|}{ Anxiety } & \multicolumn{2}{|c|}{ Depression } \\
\hline & OR (95\% Cl) & $\boldsymbol{P}$ & OR (95\% Cl) & $P$ \\
\hline \multicolumn{5}{|c|}{ How long one can persist with your current intensity of work } \\
\hline \multicolumn{5}{|l|}{$<1$ month } \\
\hline$\geq 1$ month & $0.41(0.28-0.60)$ & $<0.01$ & $0.42(0.28-0.62)$ & $<0.01$ \\
\hline Perceived distress at work & $1.18(1.11-1.26)$ & $<0.01$ & $1.14(1.07-1.21)$ & $<0.01$ \\
\hline Perceived tension & $1.11(1.07-1.15)$ & $<0.01$ & $1.11(1.07-1.15)$ & $<0.01$ \\
\hline Overcommitment & $1.20(1.10-1.31)$ & $<0.01$ & $1.10(1.01-1.19)$ & $<0.01$ \\
\hline
\end{tabular}

Cl, confidence interval; OR, odds ratio.

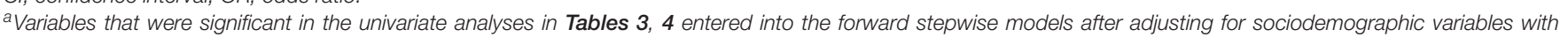
propensity score matching (sex, age, a child $<6$ years, job title and institution).

the COVID-19 epidemic are shown in Table 5. In the multivariate stepwise logistic regression analysis, persistence for more than 1 month at the current work intensity (OR $=0.41 \sim 0.42, P<0.001)$ was a significant protective factor against anxiety and depression symptoms, while perceived destress at work $(\mathrm{OR}=1.14 \sim 1.18, P<0.001)$, perceived tension (OR $=1.11,95 \% \mathrm{CI}: 1.07-1.15, P<0.001)$, and overcommitment $(\mathrm{OR}=1.10 \sim 1.20, P<0.001)$ were positively associated with anxiety and depression.

\section{Bayesian Network Models}

According to the result of the multivariate stepwise logistic regression analysis, anxiety and depression had the same 4 influencing factors. Table 6 lists and assigns these 4 influencing factors and outcome variables, which were used in the BN analysis. Figures 1, 2 show BN models of the influencing factors of anxiety and depression symptoms among public health workers during the COVID-19 epidemic, respectively. Persistence, tension, and difficulty directly affected both anxiety and depression.

Overcommitment was dependent on tension and difficulty. Tension was dependent on difficulty. Difficulty was dependent on persistence. Health status (anxiety and depression) and overcommitment were conditionally independent of tension.

\section{Conditional Probability Distribution}

Tables 7, 8 are conditional probability tables. Because of limited space, we present only a random selection of the conditional probability results.

As shown in Tables 7, 8, P (anxiety $=1 \mid$ difficulty $=2$, tension $=2$, persistence $=1) \approx \mathrm{P}($ anxiety $=1 \mid$ difficulty $=2$, tension $=2$, persistence $=2)=0.81, \mathrm{P}($ depression $=1 \mid$ difficulty $=2$, tension $=2$, persistence $=1)=0.81$, and $\mathrm{P}$ $($ depression $=1 \mid$ difficulty $=2$, tension $=2$, persistence $=2)=0.79$. Through this expression, we can draw the following conclusions. If persistence at the current work intensity occurred for more or less than a month and the scores of perceived troubles at work and perceived tension were high, the probabilities of anxiety and depression were very high (0.81 and 0.79-0.81, respectively).
TABLE 6 | Variable descriptions and assignments.

\begin{tabular}{|c|c|c|}
\hline Variables & Name & Variable assignment \\
\hline $\begin{array}{l}\text { How long one can } \\
\text { persist with your } \\
\text { current intensity of } \\
\text { work }\end{array}$ & Persistence & $<1$ month $=1, \geq 1$ month $=2$ \\
\hline $\begin{array}{l}\text { Perceived distress at } \\
\text { work }\end{array}$ & Difficulty & $\begin{array}{l}\text { The final score in the lower } \\
\text { two-thirds of the range = } 1 \text { (low } \\
\text { level), the final score in the upper } \\
\text { third of the range }=2 \text { (high level) }\end{array}$ \\
\hline Perceived tension & Tension & $\begin{array}{l}\text { The final score in the lower } \\
\text { two-thirds of the range = } 1 \text { (low } \\
\text { level), the final score in the upper } \\
\text { third of the range }=2 \text { (high level) }\end{array}$ \\
\hline Overcommitment & Overcommitment & $\begin{array}{l}\text { The final score in the lower } \\
\text { two-thirds of the range = } 1 \text { (low } \\
\text { level), the final score in the upper } \\
\text { third of the range = } 2 \text { (high level) }\end{array}$ \\
\hline Anxiety & Anxiety & $\begin{aligned} \text { GAD-7 score } & <5=0, \text { GAD-7 score } \\
\geq 5 & =1\end{aligned}$ \\
\hline Depression & Depression & $\begin{aligned} \text { PHQ-9 score } & <5=0, \text { PHQ-9 score } \\
\geq 5 & =1\end{aligned}$ \\
\hline
\end{tabular}

\section{DISCUSSION}

The present results show that during the COVID-19 epidemic, mental health problems were prominent among public health workers, with $49.2 \%$ and $45.7 \%$ suffering from anxiety and depression, respectively. These high prevalence rates were similar to the rates reported in a previous study, which found that the prevalence of anxiety and depression among 1,563 medical staff were $44.7 \%$ and $50.7 \%$, respectively, using the same measurements and cutoff points (Liu et al., 2020). The mental health of public health workers during the COVID-19 epidemic is of great concern.

Before PSM, there were demographic differences between the groups with different health conditions (anxiety and non-anxiety, depression and non-depression). Research variables related to COVID-19 (e.g., knowledge mastery, perceived troubles at work, perceived tension) may be affected by demographic factors (e.g., age, sex, and professional title). Thus, it is difficult to accurately assess the influence of COVID-19-related variables on mental 


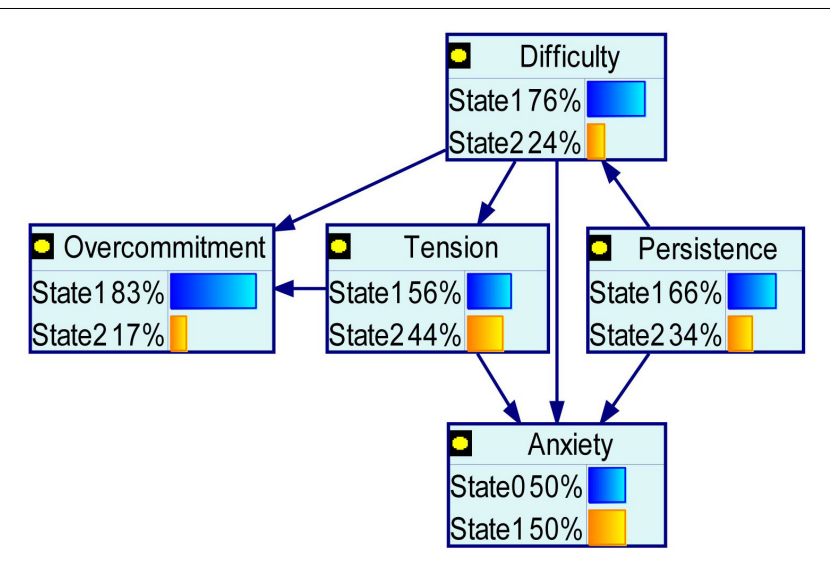

FIGURE 1 | Bayesian network for anxiety. Anxiety and the significant COVID-19-related variables in the multivariate analyses after propensity score matching entered into Bayesian network.

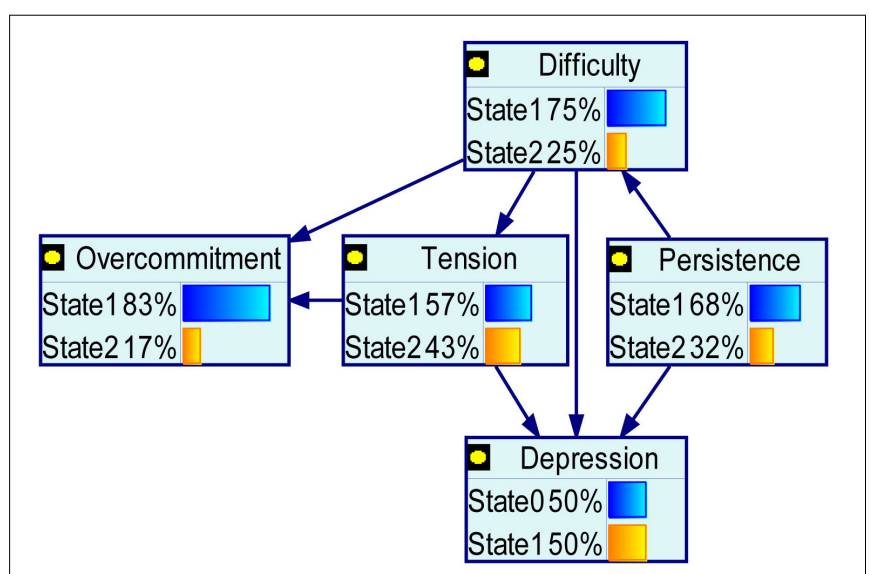

FIGURE 2 | Bayesian network for depression. Depression and the significant COVID-19-related variables in the multivariate analyses after propensity score matching entered into Bayesian network.

health status. For reasons involving time and cost, most of the current studies on mental health among various populations during the epidemic are retrospective studies, which cannot be randomized to control for confounding factors to reduce their interference with outcome effect estimates. Therefore, by using PSM to control for confounding factors, the relationships between COVID-19-related variables and the mental health of public health workers could be thoroughly explored.

Univariate analysis after PSM showed that public health workers in the anxiety and depression group were more likely to work 9-15 h and sleep an average of 5-6 h per day than to work 8 or fewer hours and sleep more than 6 h per day. Working long hours potentially reduces the sleep time of public health workers (Marjanovic et al., 2007; Afonso et al., 2017). Those who reported insufficient sleep had adverse mental health effects, similar to the findings in other studies (Simon et al., 2020). During the most severe period of the epidemic in China, a study noted that medical workers had insufficient time to rest (Chen et al., 2020). Public
TABLE 7 | Conditional probability of anxiety.

\begin{tabular}{lcccc}
\hline Difficulty & Tension & Persistence & \multicolumn{2}{c}{ Anxiety } \\
\cline { 4 - 5 } & & & $\mathbf{0}$ & $\mathbf{1}$ \\
\hline 1 & 1 & 1 & 0.61 & 0.39 \\
1 & 1 & 2 & 0.87 & 0.13 \\
2 & 1 & 1 & 0.31 & 0.69 \\
2 & 1 & 2 & 0.33 & 0.67 \\
1 & 2 & 1 & 0.30 & 0.70 \\
1 & 2 & 2 & 0.49 & 0.51 \\
2 & 2 & 1 & 0.19 & 0.81 \\
2 & 2 & 2 & 0.19 & 0.81 \\
\hline
\end{tabular}

Variable assignments are shown in Table 6.

TABLE 8 | Conditional probability of depression.

\begin{tabular}{lcccc}
\hline Difficulty & Tension & Persistence & \multicolumn{2}{c}{ Depression } \\
\cline { 4 - 5 } & & & $\mathbf{0}$ & $\mathbf{1}$ \\
\hline 1 & 1 & 1 & 0.59 & 0.41 \\
1 & 1 & 2 & 0.83 & 0.17 \\
2 & 1 & 1 & 0.43 & 0.57 \\
2 & 1 & 2 & 0.63 & 0.37 \\
1 & 2 & 1 & 0.31 & 0.69 \\
1 & 2 & 2 & 0.50 & 0.50 \\
2 & 2 & 1 & 0.19 & 0.81 \\
2 & 2 & 2 & 0.21 & 0.79 \\
\hline
\end{tabular}

Variable assignments are shown in Table 6.

health workers experienced psychological distress were more likely to encounter 6-10 difficulties at work than to encounter five or less, such as poor communication (Naushad et al., 2019) and shortages of medical protective equipment (Guangming Online, 2020; World Health Organization (WHO), 2020d). Moreover, public health workers suffering from anxiety and depression tended to be the effort-reward unbalance. The reason may be that they are not widely understood or respected by the public (Hellewell et al., 2020). During the epidemic, the prevention and control work they perform, such as isolating close contacts (at home or in a designated hotel) and conducting home inspections, is often met with non-cooperation and even opposition. This conflict not only hinders prevention efforts but also has a negative impact on the mental health of public health workers. Timeconsuming paperwork and data analyses, especially in emergency situations, may further increase people's physical and mental health burdens (World Health Organization and International Labour Organisation (WHO and ILO), 2000).

To avoid potentially false associations between the research variables and the dependent variable in the univariate analysis, we performed multivariate logistic regression analysis. The results showed that the impacts of type of work, number of difficulties in COVID-19 control and prevention, average sleep time per day (hours), average work time per day (hours), and work/life balance on mental health were offset. This may be 
related to the insufficient sample size or the collinearity of independent variables.

Research has shown that overcommitment is a risk factor for declining mental health (Hinsch et al., 2019). If public health workers overexert themselves at work and fail to obtain a reward, their frustration at work increases, potentially leading to anxiety and depression. Public health workers in anxious and depressed states had increased scores for perceived distress; these states were mainly due to their work not being understood, feeling wronged and unfairly treated at work, and regular work pressure. These factors may be related to poor social support, high labor intensity, and high personal costs among public health workers. In the fight against COVID-19, public health workers have been under tremendous pressure and are overworked and exhausted from long hours of intense work, while worrying about themselves and their families contracting the infection (Kang et al., 2020). Persistent internal physical and mental tension may manifest as psychotic symptoms in many public health workers during the epidemic.

Given that a multivariate logistic regression analysis usually considers each influencing factor under the assumption of independence and reveals only the independent factors influencing mental health, a BN model was used to construct a network diagram and conditional probability table to further describe how each factor was interrelated and affected the occurrence of anxiety and depression. The time at current work intensity, perceived troubles at work, and perceived tension were directly related to anxiety and depression, consistent with the results of the multivariate logistic regression analysis.

Mental health issues affect the attention, understanding, and decision-making abilities of public health workers, thereby hindering the fight against COVID-19 and affecting their overall health. Therefore, various interventions should be established to protect the mental health of public health workers. For example, the unit should reasonably schedule working hours, recruit volunteers with medical backgrounds and provide adequate training, thereby distributing the burden of basic public health work and relieving work-related pressure on public health workers. Moreover, social support and public awareness of the importance of public health work should be increased through media campaigns. The difficulties encountered by public health workers should be reduced by the provision of adequate protective equipment, the simplification of reporting data and the introduction of a

\section{REFERENCES}

Afonso, P., Fonseca, M., and Pires, J. F. (2017). Impact of working hours on sleep and mental health. Occupat. Med. 67, 377-382. doi: 10.1093/occmed/kqx054

Aghaabbasi, M., Shekari, Z. A., Shah, M. Z., Olakunle, O., Armaghani, D. J., and Moeinaddini, M. (2020). Predicting the use frequency of ride-sourcing by off-campus university students through random forest and Bayesian network techniques. Transport. Res. Part A 136, 262-281. doi: 10.1016/j.tra.2020.04.013

Akaike, H. (1974). A new look at the statistical model identification. IEEE Transact. Autom. Cont. 19, 716-723. doi: 10.1109/TAC.1974.1100705

Bai, Y., Lin, C. C., Lin, C. Y., Chen, J. Y., Chue, C. M., and Chou, P. (2004). Survey of stress reactions among health care workers involved with the SARS outbreak. Psychiat. Serv. 55, 1055-1057. doi: 10.1176/appi.ps.55.9.1055 reasonable and fair system of rewards and punishments. Finally, timely psychological interventions targeting public health workers should be implemented to alleviate stress during the epidemic.

This study has several limitations. First, our study was a crosssectional study that extracted data from only one point in time. Changes in the mental health status of public health workers in different periods during the epidemic should be investigated. Second, to prevent the potential spread of COVID-19, an online questionnaire was administered. Therefore, there was nonresponse bias in the study. Third, all the measures relied on self-reported questionnaires, which are dependent on individuals' subjective accounts and are vulnerable to reporting bias.

\section{DATA AVAILABILITY STATEMENT}

The original contributions presented in the study are included in the article/supplementary material, further inquiries can be directed to the corresponding author/s.

\section{ETHICS STATEMENT}

The studies involving human participants were reviewed and approved by the Chongqing Medical University. Written informed consent for participation was not required for this study in accordance with the National Legislation and the Institutional Requirements.

\section{AUTHOR CONTRIBUTIONS}

JG and HZ were responsible for conceiving and designing the study. XJ and QZ collected the data. XP and YP conducted statistical analyses and drafted the manuscript. XP and DD commented and revised the manuscript. All authors contributed, reviewed, and approved the final manuscript.

\section{ACKNOWLEDGMENTS}

We greatly appreciate all front line public health workers for their participation in this study.

Beaudequin, D., Can, A. T., Dutton, M., Jones, M., Gallay, C., Schwenn, P., et al. (2020). Predicting therapeutic response to oral ketamine for chronic suicidal ideation: a Bayesian network for clinical decision support. BMC Psychiatry 20:519. doi: 10.1186/s12888-020-02925-1

Cai, Q., Feng, H., Huang, J., Wang, M., Wang, Q., Lu, X., et al. (2020). The mental health of frontline and non-frontline medical workers during the coronavirus disease 2019 (COVID-19) outbreak in China: A casecontrol study. J. Affect. Disord. 275, 210-215. doi: 10.1016/j.jad.2020. 06.031

Charlson, F., van Ommeren, M., Flaxman, A., Cornett, J., Whiteford, H., and Saxena, S. (2019). New WHO prevalence estimates of mental disorders in conflict settings: a systematic review and meta-analysis. Lancet 394, 240-248. doi: 10.1016/S0140-6736(19)30934-1 
Chen, Q., Liang, M., Li, Y., Guo, J., Fei, D., Wang, L., et al. (2020). Mental health care for medical staff in China during the COVID-19 outbreak. Lancet. Psychiatry 7, 15-16. doi: 10.1016/S2215-0366(20)30078-X

Cowling, B. J., Ng, D. M., Ip, D. K., Liao, Q., Lam, W. W., Wu, J. T., et al. (2010). Community psychological and behavioral responses through the first wave of the 2009 influenza $\mathrm{A}(\mathrm{H} 1 \mathrm{~N} 1)$ pandemic in Hong Kong. J. Infect. Dis. 202, 867-876. doi: 10.1086/655811

Donaldson, L. (2008). The UK public health system: change and constancy. Public Health 122, 1032-1034. doi: 10.1016/j.puhe.2008.05.001

Dong, Y., Mo, X., Hu, Y., Qi, X., Jiang, F., Jiang, Z., et al. (2020). Epidemiology of COVID-19 Among Children in China. Pediatrics 145:e20200702. doi: 10.1542/ peds.2020-0702

Du Prel, J. B., Runeson-Broberg, R., Westerholm, P., Alfredsson, L., Fahlén, G., Knutsson, A., et al. (2018). Work overcommitment: Is it a trait or a state? Internat. Arch. Occupat. Env. Health 91, 1-11. doi: 10.1007/s00420-017-1253-8

García-Herrero, S., Lopez-Garcia, J. R., Herrera, S., Fontaneda, I., Báscones, S. M., and Mariscal, M. A. (2017). The Influence of Recognition and Social Support on European Health Professionals' Occupational Stress: A Demands-ControlSocial Support-Recognition Bayesian Network Model. BioMed Res. Internat. 2017:4673047. doi: 10.1155/2017/4673047

Guangming Online (2020). Over 3,000 medical staff in Hubei were infected in the early stage of the epidemic, currently no infection reports among medical aid staff. Beijing: Central Steering Group.

Hellewell, J., Abbott, S., Gimma, A., Bosse, N. I., Jarvis, C. I., Russell, T. W., et al. (2020). Feasibility of controlling COVID-19 outbreaks by isolation of cases and contacts. Lancet. Glob. Health 8, 488-496. doi: 10.1016/S2214-109X(20)300747

Hinsch, D. M., Spanier, K., Radoschewski, F. M., and Bethge, M. (2019). Associations between overcommitment, effort-reward imbalance and mental health: findings from a longitudinal study. Internat. Arch. Occupat. Env. Health 92, 559-567. doi: 10.1007/s00420-018-1391-7

Hou, T., Zhang, T., Cai, W., Song, X., Chen, A., Deng, G., et al. (2020). Social support and mental health among health care workers during Coronavirus Disease 2019 outbreak: A moderated mediation model. PLoS One 15:e233831. doi: 10.1371/journal.pone.0233831

Kang, L., Li, Y., Hu, S., Chen, M., Yang, C., Yang, B. X., et al. (2020). The mental health of medical workers in Wuhan, China dealing with the 2019 novel coronavirus. Lancet. Psychiatry 7:e14. doi: 10.1016/S2215-0366(20)30047-X

Kisely, S., Warren, N., McMahon, L., Dalais, C., Henry, I., and Siskind, D. (2020). Occurrence, prevention, and management of the psychological effects of emerging virus outbreaks on healthcare workers: rapid review and metaanalysis. BMJ 369:1642. doi: 10.1136/bmj.m1642

Koller, D., and Friedman, N. (2009). Probabilistic Graphical Models: Principles and Techniques. Cambridge, MA: MIT Press.

Kroenke, K., Spitzer, R. L., and Williams, J. B. (2001). The PHQ-9: validity of a brief depression severity measure. J. Gen. Intern. Med. 16, 606-613. doi: 10.1046/j.1525-1497.2001.016009606.x

Lai, J., Ma, S., Wang, Y., Cai, Z., Hu, J., Wei, N., et al. (2020). Factors Associated With Mental Health Outcomes Among Health Care Workers Exposed to Coronavirus Disease 2019. JAMA Netw. Open 3:e203976. doi: 10. 1001/jamanetworkopen.2020.3976

Larrañaga, P., and Moral, S. (2011). Probabilistic graphical models in artificial intelligence. Elsev. Sci. 11, 1511-1528. doi: 10.1016/j.asoc.2008.01.003

Lee, A. M., Wong, J. G., McAlonan, G. M., Cheung, V., Cheung, C., Sham, P. C., et al. (2007). Stress and psychological distress among SARS survivors 1 year after the outbreak. Canadian journal of psychiatry. Revue Can. de Psychiatrie 52, 233-240. doi: 10.1177/070674370705200405

Lee, S. M., Kang, W. S., Cho, A. R., Kim, T., and Park, J. K. (2018). Psychological impact of the 2015 MERS outbreak on hospital workers and quarantined hemodialysis patients. Compreh. Psychiatry 87, 123-127. doi: 10. 1016/j.comppsych.2018.10.003

Li, J., Wang, Y., Gilmour, S., Wang, M., Yoneoka, D., Wang, Y., et al. (2020). Estimation of the epidemic properties of the 2019 novel coronavirus: a mathematical modeling study. SSRN Electr. J. 2020:3542150. doi: 10.2139/ssrn. 3542150

Liu, S., Yang, L., Zhang, C., Xiang, Y. T., Liu, Z., Hu, S., et al. (2020). Online mental health services in China during the COVID-19 outbreak. Lancet. Psychiatry 7, 17-18. doi: 10.1016/S2215-0366(20)30077-8
Manh Than, H., Minh Nong, V., Trung Nguyen, C., Phu Dong, K., Ngo, H. T., Thu Doan, T., et al. (2020). Mental Health and Health-Related Quality-of-Life Outcomes Among Frontline Health Workers During the Peak of COVID-19 Outbreak in Vietnam: A Cross-Sectional Study. Risk Manag. Healthcare Policy 13, 2927-2936. doi: 10.2147/RMHP.S280749

Marjanovic, Z., Greenglass, E. R., and Coffey, S. (2007). The relevance of psychosocial variables and working conditions in predicting nurses' coping strategies during the SARS crisis: an online questionnaire survey. Internat. J. Nurs. Stud. 44, 991-998. doi: 10.1016/j.ijnurstu.2006.02.012

Naushad, V. A., Bierens, J. J., Nishan, K. P., Firjeeth, C. P., Mohammad, O. H., Maliyakkal, A. M., et al. (2019). A Systematic Review of the Impact of Disaster on the Mental Health of Medical Responders. Prehosp. Dis. Med. 34, 632-643. doi: 10.1017/S1049023X19004874

Neapolitan, R. E. (2004). Learning Bayesian Networks. Hoboken, NJ: Prentice Hall Press.

Niedhammer, I., Tek, M. L., Starke, D., and Siegrist, J. (2004). Effort-reward imbalance model and self-reported health: cross-sectional and prospective findings from the GAZEL cohort. Soc. Sci. Med. 58, 1531-1541. doi: 10.1016/ S0277-9536(03)00346-0

Pappa, S., Ntella, V., Giannakas, T., Giannakoulis, V. G., Papoutsi, E., and Katsaounou, P. (2020). Prevalence of depression, anxiety, and insomnia among healthcare workers during the COVID-19 pandemic: A systematic review and meta-analysis. Brain Behav. Immun. 88, 901-907. doi: 10.1016/j.bbi.2020.05.026

Pappas, G., Kiriaze, I. J., Giannakis, P., and Falagas, M. E. (2009). Psychosocial consequences of infectious diseases. Clin. Microb. Infect. 15, 743-747. doi: 10. 1111/j.1469-0691.2009.02947.x

Patel, V., Saxena, S., Lund, C., Thornicroft, G., Baingana, F., Bolton, P., et al. (2018). The Lancet Commission on global mental health and sustainable development. Lancet 392, 1553-1598. doi: 10.1016/S0140-6736(18) 31612-X

Rubin, D. B., and Thomas, N. (1996). Matching using estimated propensity score: relating theory to practice. Biometrics 52, 249-264. doi: 10.2307/2533160

Scutari, M., and Denis, J. B. (2014). Bayesian Networks: With Examples in R. London: Chapman and Hall Press.

Siegrist, J. (2008). Effort-reward imbalance and health in a globalized economy. SJWEH Suppl. 6, 163-168. doi: 10.1177/1403494807085304

Siegrist, J., and Li, J. (2016). Associations of Extrinsic and Intrinsic Components of Work Stress with Health: A Systematic Review of Evidence on the EffortReward Imbalance Model. Internat. J. Env. Res. Public Health 13:432. doi: 10. 3390/ijerph13040432

Simon, E. B., Rossi, A., Harvey, A. G., and Walker, M. P. (2020). Overanxious and underslept. Nat. Hum. Behav. 4, 100-110. doi: 10.1038/s41562-019-0754-8

Spitzer, R. L., Kroenke, K., Williams, J. B., and Löwe, B. (2006). A brief measure for assessing generalized anxiety disorder: the GAD7. Archiv. Intern. Med. 166, 1092-1097. doi: 10.1001/archinte.166.10. 1092

Taha, S., Matheson, K., Cronin, T., and Anisman, H. (2014). Intolerance of uncertainty, appraisals, coping, and anxiety: the case of the 2009 H1N1 pandemic. Br. J. Health Psychol. 19, 592-605. doi: 10.1111/bjhp. 12058

Wainberg, M. L., Scorza, P., Shultz, J. M., Helpman, L., Mootz, J. J., Johnson, K. A., et al. (2017). Challenges and Opportunities in Global Mental Health: a Research-to-Practice Perspective. Curr. Psychiatry Rep. 19:28. doi: 10.1007/ s11920-017-0780-z

Wang, C., Horby, P. W., Hayden, F. G., and Gao, G. F. (2020). A novel coronavirus outbreak of global health concern. Lancet 395, 470-473. doi: 10.1016/S01406736(20)30185-9

Wang, W., Bian, Q., Zhao, Y., Li, X., Wang, W., Du, J., et al. (2014). Reliability and validity of the Chinese version of the Patient Health Questionnaire (PHQ9) in the general population. Gen. Hosp. Psychiatry 36, 539-544. doi: 10.1016/j. genhosppsych.2014.05.021

Wang, Y., Xu, B., Zhao, G., Cao, R., He, X., and Fu, S. (2011). Is quarantine related to immediate negative psychological consequences during the 2009 H1N1 epidemic? Gen. Hosp. Psychiatry 33, 75-77. doi: 10.1016/j.genhosppsych. 2010.11.001

World Health Organization and International Labour Organisation (WHO and ILO) (2000). Mental health and work : impact, issues and good practices. Geneva: World Health Organization. 
World Health Organization (WHO) (1991). Sample size determination in health studies: a practical manual. Geneva: World Health Organization.

World Health Organization (WHO) (2015). People's Republic of China Health System Review. Geneva: World Health Organization.

World Health Organization (WHO) (2020a). Statement on the Second Meeting of the International Health Regulations (2005) Emergency Committee Regarding the Outbreak of Novel Coronavirus (2019-nCoV). Geneva: World Health Organization.

World Health Organization (WHO) (2020b). Report of the WHO-China Joint Mission on Coronavirus Disease 2019 (COVID-19). Geneva: World Health Organization.

World Health Organization (WHO) (2020c). WHO Coronavirus Disease (COVID19) Dashboard. Geneva: World Health Organization.

World Health Organization (WHO) (2020d). Shortage of personal protective equipment endangering health workers worldwide. Geneva: World Health Organization.

Xiao, X., Zhu, X., Fu, S., Hu, Y., Li, X., and Xiao, J. (2020). Psychological impact of healthcare workers in China during COVID19 pneumonia epidemic: A multi-center cross-sectional survey investigation. J. Affect. Dis. 274, 405-410. doi: 10.1016/j.jad.2020. 05.081
Yokoyama, Y., Otsuka, K., Kawakami, N., Kobayashi, S., Ogawa, A., Tannno, K., et al. (2014). Mental health and related factors after the Great East Japan earthquake and tsunami. PLoS One 9:e102497. doi: 10.1371/journal.pone. 0102497

Conflict of Interest: The authors declare that the research was conducted in the absence of any commercial or financial relationships that could be construed as a potential conflict of interest.

Publisher's Note: All claims expressed in this article are solely those of the authors and do not necessarily represent those of their affiliated organizations, or those of the publisher, the editors and the reviewers. Any product that may be evaluated in this article, or claim that may be made by its manufacturer, is not guaranteed or endorsed by the publisher.

Copyright $\odot 2021$ Peng, Pu, Jiang, Zheng, Gu, Zhou and Deng. This is an open-access article distributed under the terms of the Creative Commons Attribution License (CC BY). The use, distribution or reproduction in other forums is permitted, provided the original author(s) and the copyright owner(s) are credited and that the original publication in this journal is cited, in accordance with accepted academic practice. No use, distribution or reproduction is permitted which does not comply with these terms. 